\title{
Professional practice models used by nurses in Portuguese hospitals
}

\author{
Modelos de exercício profissional usados pelos enfermeiros em hospitais portugueses \\ Modelos de ejercicio profesional aplicados por los enfermeros en hospitales portugueses
}

\section{Olga Maria Pimenta Lopes Ribeiro' ORCID: 0000-0001-9982-9537}

Maria Manuela Ferreira Pereira da Silva Martins" ORCID: 0000-0001-5530-3891

Daisy Maria Rizatto Tronchin"' ORCID: 0000-0003-3192-1956

João Miguel Almeida Ventura da Silvaiv ORCID: 0000-0002-8794-528X Elaine Cristina Novatzki Forte
ORCID: 0000-0002-6042-5006

'Escola Superior de Saúde de Santa Maria. Porto, Portugal. "Escola Superior de Enfermagem do Porto. Porto, Portugal. "'Universidade de São Paulo, Escola de Enfermagem. São Paulo, São Paulo, Brazil.

" Centro Hospitalar de São João. Porto, Portugal. $\checkmark$ Universidade Federal de Santa Catarina. Florianópolis, Santa Catarina, Brazil.

How to cite this article: Ribeiro OMPL, Martins MMFPS, Tronchin DMR, Silva JMAV, Forte ECN. Professional practice models used by nurses in Portuguese hospitals.

Rev Bras Enferm [Internet]. 2019;72(Suppl 1):24-31. [Thematic Issue: Work and Management in Nursing]. DOI: http://dx.doi.org/10.1590/0034-7167-2017-0670

\section{Corresponding Author:}

Olga Maria Pimenta Lopes Ribeiro

E-mail: olga.ribeiro@santamariasaude.pt

Submission: 09-25-2017

Approval: 12-21-2017

\section{RESUMO}

Objetivo: Analisar os modelos de exercício profissional usados pelos enfermeiros no contexto hospitalar. Método: Estudo descritivo com abordagem qualitativa, realizado em 19 instituições hospitalares, com a participação de 56 enfermeiros. Para a coleta de dados, foi utilizada a entrevista semiestruturada. Resultados: Da análise, emergiram como categorias: prática centrada na gestão de sinais e sintomas, em que se destacaram o modelo biomédico, a prevenção de complicações e a deteção precoce de sinais e sintomas de agravamento clínico e prática centrada nas respostas humanas dos clientes evidenciando a promoção da saúde, a promoção do autocuidado, a reconstrução da autonomia, a readaptação funcional, a capacitação dos clientes, a preparação do regresso a casa e a facilitação das transições. Considerações finais: Apesar da evolução notada em alguns contextos, ainda há um distanciamento entre os modelos praticados e os expostos, apontando para a necessidade de mudanças que garantam a estruturação e sistematização da ação profissional.

Descritores: Enfermagem; Modelos de Enfermagem; Prática Profissional; Cuidados de Enfermagem; Hospitais.

\section{ABSTRACT}

Objective: To analyze the professional practice models used by nurses in the hospital context. Method: A descriptive study with a qualitative approach was carried out in 19 hospitals with 56 nurses. Data collection was carried out by means of a semi-structured interview. Results: The following categories emerged from analysis: a practice focused on the management of signs and symptoms, where the biomedical model, prevention of complications, and early detection of signs and symptoms of clinical worsening stood out, and a practice based on patients' human responses, emphasizing health promotion, self-care promotion, autonomy reconstruction, functional rehabilitation, patients' training, preparation to return home, and facilitation of transitions. Final considerations: In spite of the evolution seen in some contexts, a distance between the models practiced and those presented is still found, which indicates the need for changes ensuring structuring and systematization of the professional practice.

Descriptors: Nursing; Nursing Models; Professional Practice; Nursing Care; Hospitals.

\section{RESUMEN}

Objetivo: Analizar los modelos de ejercicio profesional aplicados por los enfermeros en el ámbito hospitalario. Método: Estudio descriptivo de abordaje cualitativo, realizado en 19 hospitales, con la participación de 56 enfermeros. Datos recolectados mediante entrevista semiestructurada. Resultados: Del análisis surgieron las categorías: práctica enfocada en la gestión de signos y síntomas, donde se destacaron el modelo biomédico, la prevención de complicaciones y la detección precoz de signos y síntomas de agravamiento clínico; y práctica enfocada en la respuesta humana de los pacientes, evidenciándose la promoción de salud, promoción del autocuidado, reconstrucción de la autonomía, readaptación funcional, capacitación de los pacientes, preparación para volver a casa y facilitación de las transiciones. Consideraciones finales: A pesar de la evolución notada, en ciertos contextos existe aún distancia entre los modelos practicados y los expuestos, expresándose la necesidad de cambios que aseguren la estructuración y sistematización de la acción profesional.

Descriptores: Enfermería; Modelos de Enfermería; Práctica Profesional; Atención de Enfermería; Hospitales. 


\section{INTRODUCTION}

In theory, nursing development, as a discipline and a profession, has met the needs identified in the care context level. Furthermore, in Portugal, nursing evolution was in line with the theory's development, from the perspective of the legal regulation of the professional practice and the evolution seen in education. However, in spite of scientific evidence and support instruments to professional practice, nurses' attitudes and practice toward patients and families show the distance between the models presented in nursing theory and professional practice models used in practice contexts ${ }^{(1)}$.

Historically, in spite of the strong influence of Florence Nightingale, during the first half of the 20th century, in the period previous to theories' development, nursing practice was subordinated to medicine. Nursing practice was prescribed by other professionals and emphasized by tasks of ritualistic nature. In this respect, the initial job of the theoreticians aimed at clarifying what nursing was, what nurses did, and what distinguished nursing from the mere performance of tasks ${ }^{(2)}$.

Effectively, through the historical overview analysis of what nursing conceptualizations have been, it is clear that from the 1950s, some theoretical schools of thought created nursing conceptual models with the purpose of explaining "what" nurses do and "why". The diverse models, when developing formal explanations of what nursing is ${ }^{(3-5)}$, have in common a rupture with the biomedical model, and affirmation and valorization of the autonomous nursing care.

In Portugal, studies carried out in this area have shown that, despite the path taken, the biomedical model, in which nurses attribute priorities to the management of signs and symptoms of illnesses and collaborative activities with the medicine, is dominant and there are difficulties in introducing characteristic aspects of the models presented that emerged from the nursing disciplinary development in models used in professional practice, which was also found in studies carried out in other countries ${ }^{(6)}$.

In recent years, nursing was marked by a full academic and professional evolution, thus having access to resources to be more strongly respected as an autonomous profession. In addition, the care context in hospitals has changed significantly in recent years. Population aging and its inherent problems, such as chronic diseases and physical disabilities, have increased and gradually deepened the need for health care, whose fulfilment is not related to the disease already diagnosed, nor the medical treatment already prescribed, but to the nursing care provided in the transition process level experienced by individuals, whether patients or families ${ }^{(1,7)}$.

In this context, despite the need for the maximum competence of nurses in the face of their collaborative role with the medicine in the diagnosis and treatment of diseases, care needs perceived by professionals or expressed by individuals, patients, or families, increasingly lead to the nursing practice presented in theoretical model $s^{(1,4,7)}$. However, in an institution where the main objective is still the treatment of diseases, the acknowledgment of the high range of nursing practices represented an important encouragement for the development of the present study.

The dichotomy between the models presented in the nursing theory and those used in the hospital context has been corroborated by several studies carried out in the country; however, specificities of the different models used by nurses are unknown. Considering this gap, and integrated into more extensive research developed in the national context entitled "Contexts of hospital practice and nursing conceptions", the present study was carried out with the aim of responding to the following question: How do nurses express the professional practice models used at hospitals in continental Portugal?

\section{OBJECTIVE}

To analyze the professional practice models used by nurses in the hospital context.

\section{METHOD}

\section{Ethical aspects}

The present study met national and international ethical standards for research involving human subjects. The study was approved by the research ethics committees and management boards of the 19 hospital centers involved.

All participants were asked to sign an informed consent form declaring that they agreed to participate in the study and authorized the interview's recording. It was clear that their participation would be voluntary, being able to withdraw from the study at any time, without any harm. In order to ensure anonymity, all interviews were coded with the initial letter of the word interviewee, followed by a numerical order from 1 to 56 .

\section{Study design}

Based on the assumption that the understanding of nurses' professional practice in the hospital context is a complex activity, it is worth mentioning that the present study aimed at understanding the reality of the phenomena, as perceived and experienced by nurses. In this respect, a descriptive study with a qualitative approach was carried out.

\section{Study setting}

Twenty-one hospital centers in continental Portugal were invited to participate in the study, which were in line with the Public Business Entity (EPE, as per its acronym in Portuguese) management model. Considering that two of these hospitals did not agree to participate, 19 hospital centers were involved in the present study.

\section{Data source}

The purposive sampling technique was used for participants' identification. In order to ensure further deepening and understanding of the phenomena under study, the group of participants was made up of head nurses, specialist nurses, and nurses. Meeting the purpose of the sample, the three informants of each hospital were referred by the head nurse of the respective institution. The inclusion criteria were: working at the hospital for at least six months in the medicine and medical specialty units, surgery and surgery specialties units, or intensive care medicine and urgency units. 
Professional practice models used by nurses in Portuguese hospitals Ribeiro OMPL, Martins MMFPS, Tronchin DMR, Silva JMAV, Forte ECN.

After indication of the potential informants by the head nurses, they were contacted by the researcher with the purpose of validating the decision to participate in the study. Because a head nurse of one of the hospitals refused to participate, the present study was made up of a total of 56 nurses.

\section{Data collection and organization}

Data collection was carried out by means of semi-structured interviews. The meeting with the participants was previously scheduled, always according to their availability. The interviews were carried out from August 2015 to February 2016 by one of the researchers, in private spaces reserved in each hospital and with an average duration of 60 minutes. In order to check difficulties in the interpretation of the questions, previous interviews were carried out. After authorization of the participants, all interviews were recorded. Subsequently, the transcription of each participant's interview was sent by e-mail for content validation. It is worth mentioning that, according to the codification defined, I1 to I19 were interviews carried out with nurses, I20 to I38 were interviews carried out with specialist nurses, and I39 to 156 were interviews carried out with head nurses.

\section{Data analysis}

Content analysis was carried out according to guidelines of Bar$\mathrm{din}^{(8)}$ and with the use of the software Atlas.ti ${ }^{\circledR}$ version 7.5.10. In this context, the analysis of the participants'speeches was divided into three stages: pre-analysis, material exploration, and inference and interpretation. After the use of the Atlas.ti ${ }^{\circledR}$ software, identification codes were attributed (codes) to the record units (quotations) and the categories (families) were subsequently organized.

\section{RESULTS}

Regarding the 56 participants, most were women (73.2\%). Age distribution shows a prevalence of participants aged from 30 to 35 years and from 50 to 55 years, with a mean age of 42.5 years and standard deviation of 9.9. Most were married or in a stable union (73.2\%). With regard to profession, its uniform distribution met the sample's purpose, with 19 nurses (33.93\%), 19 specialist nurses (33.93\%), and 18 head nurses (32.14\%). Regarding education level, most participants had an undergraduate degree (76.8\%), followed by a master's degree (21.4\%), and a doctorate degree (1.8\%).

Two perspectives stood out during data analysis of the participants'speeches in the context of the theme professional practice guiding models, with one focused on the management of signs and symptoms and another on patients' human responses (Chart 1).

With regard to models focused on the management of signs and symptoms, a practice focused on the prevention of complications was often found in the speeches,

Everything concerning our daily work is basically focused on the prevention of complications. (I26)

I think it belongs to our essence; being a nurse means being always thinking about preventing what may happen. (146)
Chart 1 - Professional practice guiding models, Porto, Portugal, 2017

\begin{tabular}{|c|c|}
\hline Categories & Subcategories \\
\hline \multirow{3}{*}{$\begin{array}{l}\text { Practice focused on } \\
\text { the management of } \\
\text { signs and symptoms }\end{array}$} & - Prevention of complications \\
\hline & $\begin{array}{l}\text { - Early detention of clinical worsening signs } \\
\text { and symptoms }\end{array}$ \\
\hline & - Biomedical model \\
\hline \multirow{8}{*}{$\begin{array}{l}\text { Practice focused on } \\
\text { human responses }\end{array}$} & - Health promotion \\
\hline & - Self-care promotion \\
\hline & - Autonomy reconstruction \\
\hline & - Functional rehabilitation \\
\hline & - Patients' training \\
\hline & - Caregivers' training \\
\hline & - Preparation to return home \\
\hline & - Facilitation of transitions \\
\hline
\end{tabular}

In surgery and surgical specialty units, the prevention of postoperative complications was one of the most highlighted aspects,

There are things so extremely basic in a surgical unit, that they are already rooted... that working in a surgical unit, we all know how important early recovery is. (I39)

In addition, over the implementation of the interventions, it was clear that the focus is still on the prevention of complications.

In the postoperative period, we also deal with the pain of the surgical patient... We all know that pain limits anyone's mobility... Therefore, we must anticipate complications... analgesics must be administered whenever necessary to provide patients with more comfort during their recovery. (I39)

Considered as a common topic in all contexts, the prevention of complications associated with drug and blood-derivative administration, as well as technical procedures, were also approached by the participants.

There are fundamental things in our job: transfusion support... cytostatic therapy administration... antibiotic administration... If we know about these three fields and risks already identified, we are able to minimize... Applying this to several fields, we are able to prevent $70 \%$ to $80 \%$ of the complications. In addition, we have technical procedures such as peripheral venipunctures, help in the insertion of central catheters, myelograms, lumbar punctures... It is important to know about the risks, make anything to prevent them and minimize consequences... Whenever more serious things happen, we have to be quick to take action... and act quickly according to the complication degree. (I12)

In fact, in cases where it is not possible to prevent complications, the early identification of signs and symptoms may minimize the effects, and nurses' action-quickness is of utmost importance.

If I am attentive to that patient, I can quickly identify early alert signs and minimize complications, that is, I may not prevent them, but I am able to minimize their consequences. (112) 
In medical general and specialty units, the prevention of infections, falls, and pressure ulcers acquired a significant relevance in the speeches.

We are very aware of the infection prevention issue. (126)

In case of risk of falling, patients must wear wristbands... and have bed rails. (I34)

These procedures are already rooted in every element of the unit... these guidelines to prevent pressure ulcers. (153)

In complex professional practice contexts, such as the case of intensive medicine and urgency care, it was clear that the emphasis is often on the early detention of clinical worsening signs and symptoms.

At least when we must keep people alive, whenever we are meant to keep them alive... in addition to knowing how to read signs and symptoms, and complications that might emerge... even knowing that aid will come from another professional... we must know how to anticipate situations. (I3)

In fact, although nurses' performance in some situations is almost exclusively restricted to clinical worsening, data collection and performance of interventions prescribed by physicians, the participants' speeches show the meaning attributed to this dimension.

The issue is that, even in less complex contexts, data analysis shows, despite evolutions seen in recent years, a general perception that nursing is still driven by the biomedical model guided toward the performance of tasks.

We can see a focus on the acute problem... where we only deal with systematic alterations in the organic systems... and respond to prescriptions... It is the biomedical model par excellence, that is, physicians prescribe, nurses perform, and responding to these prescriptions is what matters. (I33)

Analyzing this speech, it was clear that practice has not translated the theoretical evolution of nursing.

In the last decade... several studies in the nursing area have emerged... trying to translate these studies into practice; however, we are still not able to do it... we are still working in the biomedical model. (I52)

In addition to a practice focused on the management of signs and symptoms, in the context of a practice focused on patients' human responses, the concern of some nurses in using hospitalization to promote healthy lifestyles is clear,

Although patients may be experiencing an acute illness situation... we try to teach them some ideas regarding what they must do to promote health after hospitalization... (118)

It is worth mentioning that, with the purpose of acting in the health promotion context, the information provided by nurses to patients often considers the pathological process that led to their hospitalization, as well as factors that may enhance other pathological processes.

Nurses' concern in finding the reasons why patients were hospitalized emerges... but also everything that is associated with other aspects regarding health promotion that is not effectively achieved by patients. (140)

Patients with chronic diseases who are often hospitalized, we seize the opportunity to promote... healthy habits... (I1)

In addition to the practice focused on health promotion, the investment in self-care promotion stood out, mostly related to patients who presented some dependence degree associated with physical or essentially cognitive alterations before hospitalization. Emphasis on patients' self-care capacity to the detriment of a perspective mostly focused on patients' replacement emerged as nurses' concern.

We must know how to read self-care dependence... and we must know how to replace it when it's enough, and promote it whenever possible. (I3)

For example, during hygiene care, if patients are able to wash the upper body, their chests and arms, I will only help them wash their lower limb, because that is where they often have more difficulty. (I33)

Although showing concern, nurses recognize the existence of situations where patients' replacement standards may tend to be adopted.

I feel that sometimes, patients are able to do more than they do... but sometimes, we do ourselves to save time. (I37)

The disadvantages of having two nurses to provide care to patients were also mentioned by the participants:

We do not work in pairs because it would be impractical... that is when patients are totally replaced, there is no discussion, because they want to move on and send them home. (133)

Because self-care is an area where some tasks are delegated to operational aides, it was clear that the evaluation and prioritization of the situations by nurses may make a difference. Therefore, in order to prevent repercussions of an approach focused on patients replacement, the participants show the concern in teaching and instructing adaptive strategies in a performance congruent with the models presented.

The choice is: these two or three patients need me for this, and not because they have complications, but because I want to show them that they can do this! Now, with a nursing aide giving them bath, nobody will ever show them this! (I3)

Based on the abovementioned speech, in patients with potential for autonomy who have cognitive, decision-making, mobility, and communication skills, the participants approached a practice focused on autonomy reconstruction. 
Many times, patients... that somehow, we also help them to initiate this autonomy reconstruction process. (I21)

Some people come with many limitations... but I want them to become autonomous as quickly as possible. (I29)

Due to the valorization of transitory dependency situations, where the need for help in what patients are not able to initiate or complete is seen as temporary, nurses try

To promote patients' autonomy as earlier as possible, and this autonomy is carried out with extensive teaching... (I12)

The relevance attributed to "teachings" by nurses intends to explain their purpose toward the development of patients' self-care skills, thus teaching, instructing, and training adaptive strategies for the accomplishment of activities inherent to each self-care dimension.

In spite of increasingly shorter hospitalization policies and, consequently, less contact with patients, the purpose of a practice focused on functional rehabilitation was also approached,

I work every day with patients who have respiratory problems and must learn... how to live. (I20)

The explanation refers to situations where nurses' intervention is not directed to the resolution of the condition presented by patients, but the intention of teaching strategies that promote patients' adaptation to their condition.

Every day we have to teach strategies to help them when they are home, such as how to hang their laundry, wash dishes... deeply, this is rehabilitation. Every day we have to teach strategies so they are able to perform activities of daily living. (I20)

I try to promote... strategies so patients may adapt themselves to their disabilities, and they end up accepting and achieving better recovery. (I23)

For example, amputees will have to live without a limb and... learn how to live with their situation... Therefore, nurses have an important role. (I39)

Of the constraints associated with the accomplishment of functional rehabilitation, the participants mentioned lack of time and the impossibility to maintain continuity.

There are gaps because this area demands time and continuity... in my point of view, it is essential having someone dealing directly and specifically with patients and their evolution in the units. (I38)

In order to ensure time and continuity required for functional rehabilitation, it is consensual that, in the hospital context, this area has been attributed to the rehabilitation nursing.

Here, we often delegate to rehabilitation nurses. (114)

The recognition of the skills of these specialist nurses to promote health improvements in the area in question was also identified.
We had a high percentage of patients who came standing and left bedridden or at least with significant limitations, and, today, we have many patients who... come with some limitations and leave much better... than when they came. Result from the investment of rehabilitation nurses. (I10)

Still in the context of a practice focused on human responses, investment in patients' training was mentioned.

We must focus on the training of patients who really depend on nursing intervention... it is hard to achieve this level with some patients... it highly depends on their age, mental condition, or even on previous preparation and training. Above all, I think it basically depends on nurses. (I39)

Effectively, in spite of the importance of patients' capacity to absorb information, nurses' role is of utmost importance.

\section{Patients leave here with knowledge on care... to manage enoxa- parin. (151)}

When patients undergo colostomy... teachings are always structured... then we have training... patients have to do it in our presence in order to check whether they are able or not. (I8)

In this process, two different situations stand out, that is, the transmission of theoretical information that Portuguese nurses traditionally call "teachings" and that refers to interventions in the information and teaching context, and the training of basically technical aspects, which are included in training interventions. At an intermediate level, instruction-type interventions were not mentioned, because the demonstration of the techniques by nurses is often included in what participants call "teachings". However, it is worth mentioning the reference to structured teachings.

Due to the increasingly shorter hospitalization policies, which do not allow patients'full recovery, families have been confronted by the hospital discharge of their sick family members, often with a health condition different from that before hospitalization, demanding knowledge and skills from those who will perform the role of caregivers. In line with the abovementioned, one of the first concerns that emerged from the analysis of the speeches was the identification of the person who will perform the role of caregiver.

It is a concern since the beginning... because patients may have some problems... they will have many limitations, thus being important to figure out who will be in charge of the follow-up at home. (I31)

The relevance of caregivers' training to provide care to patients who become dependent is clearly evidenced in the speeches,

I must be difficult for nurses to perform this role in caregivers training. (I21)

In fact, in addition to being a professional resource to patients, nurses have to help family members who will perform the role of caregivers to deal with the situation of providing care and its implications. It is clear that professional help is essential for the performance of the role of caregiver and acquisition of skills for its accomplishment. 
Although the speeches evidence the investment in caregivers' training, the participants also indicate the importance of this autonomous dimension, associating the idea that nurses are the health professionals who best prepare family members who will perform the role of caregivers to help patients in their self-care.

Whether wives or mothers, we have to realize how significant we are for these people and that there is nobody who... is able to prepare caregivers... to help these patients with their self-care at home. (I21)

Once the value of caregivers' training is recognized, nurses integrate the preparation to return home in their practice.

What we try to do... while they are hospitalized, is to prepare them to return home. (112)

In this context, concern with patients' adaptation at home regarding their needs as well as those of the caregivers is evidenced.

When patients return home, I try to make an evaluation of their physical space at home, I talk to their families... in order to show them what is best for that situation. (135)

Nurses' contribution to facilitating transitions was also mentioned,

We want to help people to undergo a healthful transition in order to regain balance. (120)

The following aspects were highlighted by the participants: awareness,

Our role is undoubtedly of utmost importance in the first steps, which is patients' awareness of their new health condition. (121)

Involvement,

If we talk about... what is the involvement in the problem. (120)

Change,

Patients who acquired limitations or disabilities... if patients do not internalize this new situation, it will not be healthy because the problem will always be there. (139)

Difference

In the case of an ostomy, patients have to face something totally different. (14)

Period of time,

Patients who take longer to be adapted. (I33)

And critical event,

Sometimes, before surgery, they think it is provisory, but in the postoperative period, when the physician says it is definitive, they realize that it is better to learn. (14)
In the context of facilitating and inhibiting conditions, data regarding personal conditions were identified,

The meanings attributed by patients to illnesses, hospitalizations, as well as their beliefs, are aspects that often hinder a favorable evolution. (14)

At a response pattern level, result indicators stood out, that is, skills,

As hospitalization days go by, we realize that as a result from our teachings, patients' capacity to take care of colostomies improves. (14)

And fluid integrative identity,

If we help patients in living with their limitations or... what will be definitive... we are confident that they already accepted that new situation, because they are developing their learning and even their identities. (I39)

In addition to patients' transition from a health status to an illness status, the transition experienced by families emerged, whose change will be more intensely shown in the person that will assume the responsibility of caregiver.

We must be significant for the families, we have to find someone there willing to play a role that, many times, was not expected to be played so soon. (I21)

\section{DISCUSSION}

Regardless of care contexts, there are different nursing practices $^{(9)}$, and, in this respect, there is no single model, but several models in use. The present study showed that professional practice guiding models in the hospital context are influenced by two perspectives, one theoretical and one practical.

At the theoretical perspective level, there is double influence, which basically results from theoretical frameworks that have emerged over the conceptual development of nursing in an international context, as well as from regulating instruments that emerged during the development of the nursing profession in Portugal. Regarding the practical perspective, the influence derives essentially from the professional development of nursing closely with medicine, in a clear trend toward the biomedical model.

Effectively, there is as a significant number of contexts where practice tends to be focused on the prevention of complications and early detention of clinical worsening, which is translator of alterations in physical processes. As a consequence, nursing care in the hospital context has been compromised, because it reflects a performance focused on signs and symptoms ${ }^{(10)}$, prevailing the logic of the units to the detriment of patients' needs ${ }^{(11)}$. In this context, due to a care provision focused on tasks, a fragmented and automated practice is often seen, which hinders the removal of the biomedical model.

However, in 2003, when the quality care model was presented, nursing was still driven by the biomedical model ${ }^{(12)}$. Recently, in one study carried out in the hospital context, nurses reported that their academic and professional path had been strongly 
Professional practice models used by nurses in Portuguese hospitals Ribeiro OMPL, Martins MMFPS, Tronchin DMR, Silva JMAV, Forte ECN.

directed toward the development of skills, basically focused on the management of signs and symptoms of diseases and a very clear proximity to the biomedical model ${ }^{(13)}$. In fact, the models focused on the management of signs and symptoms and collaboration with physicians in the treatment of disorders seem to be currently in line with the difficulties experienced by nurses ${ }^{(14)}$.

In spite of the long theorizing path emphasizing a gradual distance from the biomedical model, the application of these assumptions in the care provided to patients does not translate the same evolution. In Portugal, nursing practice is still guided toward the management of signs and symptoms, and prevention of complications associated with surgeries, medication, and disorders, as evidenced in the findings of the present study.

However, the biomedical model that supported, and still supports in some institutions, a care conception restricted to the management of signs and symptoms has proved insufficient to meet patients' more recent needs ${ }^{(9,14)}$. In fact, in recent years, in the hospital context, specific and depersonalized care provision directed toward cases rather than patients and families, in an intervention preferably dedicated to the resolution of acute diseases ${ }^{(1)}$, has proved deeply inappropriate to the real needs of the population ${ }^{(15)}$.

In addition, in the context of a practice focused on the prevention of complications, the fact of the prevention of infections, falls, and pressure ulcers being indicators in the area of quality accreditation processes implemented in hospitals, makes nurses support their practice on procedures of the institution, to the detriment of the identification of nursing diagnoses based on the relevance of the data inherent to patients' conditions.

In the context of professional practice models guided toward human responses, the emphasis on a practice focused on health promotion and functional rehabilitation evidences nurses' concern in performing in line with quality standards of nursing care ${ }^{(16)}$. However, the guiding models focused on self-care and transitions indicate that assumptions inherent to the medium-range transition theory ${ }^{(17)}$ and self-care deficit theory ${ }^{(3)}$ have been applied in practice ${ }^{(18)}$.

\section{Study limitations}

In the sequence of a purposive sampling, knowledge of head nurses on their subordinate nurses was used, and the profile of the nurses selected may have influenced the results of the present study. However, in general, the findings evidence the professional practice models used by nurses in the hospital contexts of continental Portugal.

\section{Contributions to the nursing area}

In spite of the relevance attributed to healthcare areas in the nursing field, over the development of the present study, it was clear that practice does not reflect nursing development, thus evidencing a distance between the models practiced in the professional context and those proposed. Although this depends on aspects associated with practice environments, it seems to be significantly influenced by nurses. Therefore, factors that determine or condition guidance toward a practice focused on the management of signs and symptoms or a practice focused on patients' human responses must be identified.

\section{FINAL CONSIDERATIONS}

Although the integration in practice of aspects inherent to the theory exposed is clear in some contexts, such as the emphasis on self-care, transition processes, preparation to return home, and the role of family members as caregivers, aspects that end up conditioning the necessary structuring and systematization of professional performance emerged simultaneously from the participants' speeches, whose repercussion is evident in the description of incomplete and fragmented practice often based on poor arguments and sometimes rather inconsistent, thus demanding reflection and changes in practice.

Therefore, nursing in Portugal, although with differences among hospitals, experiences a transition moment between a practice still strongly inspired by the biomedical model, and a practice already visible, although not expanded to all contexts, where the influence of the theoretical frameworks of the nursing discipline is clear.

\section{REFERENCES}

1. Fernandes CS, Gomes JA, Martins MM, Gomes BP, Gonçalves LH. The Importance of Families in Nursing Care: Nurses' Attitudes in the Hospital Environment. Rev Enf Ref [Internet]. 2015 [cited 2017 Fev 05];IV(7):21-30. Available from: http://www.scielo.mec.pt/pdf/ref/ vserlVn7/serlVn7a03.pdf Portuguese

2. McEwen M, Wills EM. Theoretical Basis for Nursing. 4th ed. Philadelphia: Lippincott Williams \& Wilkins; 2014 . 592 p.

3. Shah M. Compare and Contrast of Grand Theories: Orem's Self-Care Deficit Theory and Roy's Adaptation Model. Int J Nurs Didac. 2015;5(1):39-42. doi: http://dx.doi.org/10.15520/ijnd.2015.vol5.iss01.28.39-42

4. Salviano MEM, Nascimento PDFS, Paula MA, Vieira CS, Frison SS, Maia MA, et al. Epistemology of nursing care: a reflection on its foundations. Rev Bras Enferm [Internet]. 2016 [cited 2017 Mar 01]; 69(6):1172-7. Available from: http://www.scielo.br/pdf/reben/v69n6/en_0034-7167reben-69-06-1240.pdf

5. McCrae N. Whither Nursing Models? The value of nursing theory in the context of evidence-based practice and multidisciplinary health care. J Adv Nurs [Internet]. 2011 [cited 2017 Fev 24]; 68(1):222-9. Available from: http://onlinelibrary.wiley.com/doi/10.1111/j.13652648.2011.05821.x/epdf?r3_referer=wol\&tracking_action=preview_click\&show_checkout=1\&purchase_site_license=LICENSE_DENIED_ NO_CUSTOMER

6. Zarzycka D, Dobrowolska B, Wron'ska I, Cuber T, Pajnkihar, M. Theoretical foundations of nursing practice in Poland. Nurs Sci Q. 2013;26(1), 
Professional practice models used by nurses in Portuguese hospitals Ribeiro OMPL, Martins MMFPS, Tronchin DMR, Silva JMAV, Forte ECN.

80-84. doi: 10.1177/0894318412466736

7. Paiva A. Prefácio. In: Martins T, Araújo MF, Peixoto MJ, Machado PP, organizadores. A pessoa dependente e o familiar cuidador. Porto: Escola Superior de Enfermagem do Porto; 2016. p. 5-7.

8. Bardin L. Análise de Conteúdo. Lisboa: Edições 70; 2015.

9. Rodrigues FRA, Pereira MLD, Amendoeira J. Paradigmatic transition of health and reflections in nursing as a discipline. Rede Cuidados Saúde [Internet]. 2015 [cited 2017 Mar 03]; 9(1):01-08. Available from: http://publicacoes.unigranrio.com.br/index.php/rcs/article/view/2516/1281

10. Benedet SA, Gelbcke FL, Amante LN, Padilha MI, Pires DEP. Nursing process: systematization of the nursing care instrument in the perception of nurses. Rev Pesqui Cuid Fundam [Internet]. 2016 [cited 2017 Mar 02];8(3):4780-8. Available from: http://www.seer.unirio.br/ index.php/cuidadofundamental/article/view/4237/pdf

11. Souza MF, Santos AD, Monteiro Al. The nursing process in the opinion of the nursing staff of a teaching hospital. Rev Bras Enferm [Internet]. 2013 [cited 2017 Mar 03];66(2):167-73. Available from: http://www.scielo.br/pdf/reben/v66n2/03.pdf

12. Duffy JR, Hoskins LM. The Quality-Caring Model@: Blending Dual Paradigms. Adv Nurs Sci. 2003;26(1):77-88. doi: 10.1097/00012272-200301000-00010

13. Padilha JM. Promoting self-care management in patients with Chronic Obstructive Pulmonary Disease (COPD): a path of action research. Interface Comun Saúde Educ [Internet]. 2015 [cited 2017 Fev 03];19(52):201-2. Available from: http://www.scielo.br/pdf/icse/ v19n52/en_1807-5762-icse-19-52-0201.pdf

14. Sousa MR, Martins T, Pereira F. Reflecting on the practices of nurses in approaching the person with a chronic illness. Rev Enf Ref [Internet]. 2015 [cited 2017 Fev 21]; IV(6):55-63. Available from: http://www.scielo.mec.pt/pdf/ref/vserlVn6/serlVn6a07.pdf

15. Ribeiro OM, Pinto CA, Regadas SC. People dependent on self-care: implications for nursing. Rev Enf Ref [Internet]. 2014 [cited 2017 Fev 07];IV(1):25-36. Available from: http://www.scielo.mec.pt/pdf/ref/vserlVn1/serlVn1a04.pdf

16. Martins MM, Gonçalves MN, Ribeiro OM, Tronchin DM. Quality of nursing care: instrument development and validation. Rev Bras Enferm [Internet]. 2016 [cited 2017 Fev 27];69(5):864-70. Available from: http://www.scielo.br/pdf/reben/v69n5/en_0034-7167-reben-69-05-0920.pdf

17. Meleis Al, Sawyer LM, Im EO, Messias DK, Schumacher K. Experiencing transitions: an emerging middle-range theory. Adv Nurs Sci [Internet]. 2000 [cited 2017 Fev 22]; 23(1):12-28. Available from: https://www.researchgate.net/ publication/12352146_Experiencing_Transitions_An_Emerging_Middle-Range_Theory

18. Ribeiro OMPL. Contextos da prática hospitalar e conceções de enfermagem: olhares sobre o real da qualidade e o ideal da excelência no exercício profissional dos enfermeiros [Thesis on the Internet]. Porto: Instituto de Ciências Biomédicas Abel Salazar; 2017 [cited 2018 Aug 31]. 400 p. Available from: https://repositorio-aberto.up.pt/bitstream/10216/105835/2/202221.pdf 